\title{
EL PROBLEMA DE LAS FALACIAS: OBJECIONES A LA UTILIDAD DE UN CONCEPTO TEÓRICO
}

\author{
THE PROBLEM OF FALLACIES: OBJECTIONS TO \\ THE USEFULNESS OF A THEORETICAL CONCEPT
}

\author{
José Ángel Gascón \\ Departamento de Filosofía, \\ Universidad Católica del Maule, \\ Talca, Chile \\ jgasconducm.cl
}

Aunque el concepto de falacia es ampliamente utilizado tanto dentro como fuera de la filosofía, también ha sido criticado recientemente por varios autores. En este artículo me uno a esas voces críticas con el objetivo de presentar varias razones para abandonar el concepto de falacia en teoría de la argumentación. Argumentaré que la noción de falacia está intrínsecamente unida a las taxonomías de falacias, y tales taxonomías resultan ser muy deficientes para distinguir argumentos genuinamente defectuosos. Los esquemas argumentativos falaces identifican tanto buenos como malos argumentos, de modo que carece de sentido mantener tales esquemas o tipos de argumentos en las clasificaciones de falacias. En los casos en los que, en lugar de basarse exclusivamente en los esquemas argumentativos, se establecen criterios pragmáticos y contextuales que identifican inequivocamente argumentos incorrectos, tales criterios están formulados en términos evaluativos, cuya aplicación no es directa e indiscutible. En consecuencia, las etiquetas de falacias no proporcionan un fundamento teórico para distinguir entre buenos y malos argumentos y tampoco desempeñan ningún papel en nuestras evaluaciones cotidianas de argumentos, que se basan más bien en apreciaciones de aspectos del contexto para cada argumento concreto. 
126 - Cogency, Journal of reasoning and argumentation

Finalmente, responderé a la objeción de que, aunque el concepto de falacia pueda ser teóricamente problemático, la enseñanza de las falacias resulta útil para el desarrollo de las habilidades argumentativas.

Palabras clave: argumentos, esquemas argumentativos, lógica informal, términos evaluativos.

Even though the concept of fallacy is widely used both inside and outside philosophy, it has also been recently criticised by several authors. In this paper I join these critical voices with the aim of putting forward several reasons to abandon the concept of fallacy in argumentation theory. I will argue that the notion of fallacy is inextricably linked to taxonomies of fallacies, and such taxonomies turn out to be seriously deficient in order to distinguish genuinely flawed arguments. Fallacious argument schemes identify both good and bad arguments, so there is little sense in preserving those schemes or kinds of arguments in the classifications of fallacies. In those cases in which, instead of completely relying on argument schemes, pragmatic and contextual criteria are established that unequivocally identify incorrect arguments, such criteria are framed in evaluative terms, the application of which is not straightforward and uncontroversial. Hence, fallacy labels do not provide a theoretical foundation to discriminate between good and bad arguments and they play no role in our everyday evaluations of arguments, which are rather based on appreciations of aspects of the context for each particular argument. Finally, I will answer the objection that, even though the concept of fallacy might be theoretically problematic, the teaching of fallacies is useful for the development of argumentative skills.

Keywords: arguments, argument schemes, informal logic, evaluative terms. 


\section{Introducción}

Lo cierto es que hoy en día nadie está satisfecho con este rincón de la lógica. [...] No disponemos de ninguna teoría de las falacias, en el sentido en el que disponemos de teorías del razonamiento y la inferencia correctas. Charles L. Hamblin, 1970 (2016, p. 18)

En la actualidad, seguimos careciendo de una teoría cabal de la argumentación falaz, pero creo que nuestra conciencia histórica y crítica se ha vuelto más sabia. Luis Vega Reñón (2013, p. 12)

Las falacias están de moda. El surgimiento, en la segunda mitad del siglo XX, de los modernos estudios de argumentación se apoyó en buena medida en el estudio de las falacias. La obra clásica de Hamblin sobre falacias -Fallacies, de 1970- fue uno de los textos que marcaron el renacimiento actual de la teoría de la argumentación. Los inicios, en las décadas de 1970 y 1980, del movimiento de la lógica informal -que vino a reemplazar a la lógica formal como herramienta de estudio de los argumentos- consistieron en el estudio de las falacias como un medio para elaborar una teoría pertinente para la argumentación cotidiana en lenguaje natural. Así puede verse, en particular, en Logic and contemporary rhetoric (primera edición de 1971), de Kahane, y en Logical self-defense (primera edición de 1977), de Johnson y Blair, ambos textos fundacionales y que ofrecen una perspectiva de la argumentación centrada en la noción de falacia. Las falacias representan un papel igual de importante en la pragmadialéctica, la teoría surgida de la mano de van Eemeren y Grootendorst, pues su lista de reglas para el desarrollo razonable de las discusiones críticas tiene como objetivo principal detectar la comisión de falacias.

No solo las falacias ocupan un lugar central hoy en día en los estudios sobre argumentación y razonamiento, sino que -lo que resulta más significativo- también han pasado a formar parte de la cultura popular fuera de las facultades de filosofía ${ }^{1}$. Muestra de ello son los numerosos catálogos de falacias que uno puede encontrar al explorar Internet. Uno de los más completos y de más antigüedad es el que nos ofrece Ricardo García Damborenea bajo el título de "Uso de razón”, en el que se incluyen y explican más de 40 falacias². Esta

1 Aparte del sentido lógico o argumentativo de "falacia", en el habla cotidiana el término también se usa para referirse a mentiras o falsedades, pero ese sentido no nos interesa aquí. Agradezco a Hubert Marraud que llamara mi atención sobre este hecho.

2 http://www.usoderazon.com/conten/arca/dicci/dicci2.htm 
web define las falacias como "todas las formas de argumentación que encierran errores o persiguen fines espurios", e incluye desde falacias que forman parte de la tradición desde Aristóteles, tales como la falacia del accidente o la petición de principio, hasta otras más recientes como la falacia genética o incluso alguna ausente en los demás catálogos, como la falacia casuística.

La concepción predominante de las falacias en la cultura popular es la de tipos de argumentos que contienen algún error o son engañosos en algún sentido ${ }^{3}$. En ocasiones se usa "falacia" como sinónimo de "argumento incorrecto", pero hay una diferencia importante: las falacias identifican tipos o esquemas generales de argumentos incorrectos -por eso se pueden elaborar catálogos de falacias-. Un argumento incorrecto, en cambio, es un argumento concreto - un token-. Todas las clasificaciones de falacias presuponen la existencia de tipos o patrones de argumentos incorrectos, ya que no puede existir una clasificación (finita) de argumentos incorrectos particulares. Por lo tanto, ninguna de mis críticas hacia la noción de falacia debe interpretarse en el sentido de que no creo que haya argumentos incorrectos; mis observaciones se dirigen solo a la noción de falacia como tipos de argumentos incorrectos.

Sin duda, en la historia de la filosofía se han concebido las falacias de diferentes formas. Para Aristóteles en las Refutaciones sofísticas, las falacias -o, más bien, los sofismas o paralogismos- tenían lugar en un tipo particular de debate académico y no eran tanto errores de razonamiento como fallos estratégicos (Hamblin, 2016, p. 73; Vega Reñón, 2013, p. 148). Sea como fuere, no es esta la noción de falacia que ha calado en nuestras prácticas discursivas, sino la de un argumento que contiene un error de razonamiento debido a su estructura $\mathrm{o}$ al tipo al que pertenece.

Además, mi punto de partida es la intuición de que la noción de falacia, en su uso más extendido entre hablantes no especializados, contiene unas claras implicaciones de objetividad. Una falacia es un tipo de error serio, no un simple desacuerdo sobre la calidad de un argumento. Quien acusa a un argumentador de cometer una falacia no está sugiriendo simplemente que cree que su argumento es débil; de hecho, está implicando que su argumento contraviene algún tipo de regla lógica y por ello queda completamente invalidado. Esto se muestra en el hecho de que, generalmente, quienes hacen acusaciones de falacia no suelen acompañarlas de una contraargumentación, y a menudo tampoco proporcio-

3 Así, por ejemplo, en la entrada "Falacia" de la Wikipedia se afirma: "La falacia lógica es un modo o patrón de razonamiento que siempre o casi siempre conduce a un argumento incorrecto. Esto es debido a un defecto en la estructura del argumento que lo conduce a que este sea inválido" (consultado el 4 de julio de 2021). Asimismo, en la web "Falacias lógicas explicadas gráficamente", de la ARP-Sociedad para el Avance del Pensamiento Crítico, se ofrece la siguiente definición: "Una falacia es un razonamiento inválido o engañoso con apariencia de correcto que pretende ser convincente" (https://falacias.escepticos.es/, consultado el 4 de julio de 2021). Véase también la definición de García Damborenea, citada en el párrafo precedente. 
nan siquiera una explicación de por qué consideran que el argumento en cuestión es una falacia ${ }^{4}$. Rara vez se deja abierta la posibilidad de discutir con el argumentador los detalles de la acusación de falacia.

Esta concepción de las falacias como tipos de errores serios puede verse en teóricos de la argumentación como Douglas Walton (1995, p. 15):

\begin{abstract}
De acuerdo con la nueva teoría, una falacia es un error subyacente y sistemático o una táctica engañosa. Acusar a alguien de haber cometido una falacia en su argumento es una acusación bastante seria en cuestiones de cortesía conversacional. [...] Una falacia, entonces, no es simplemente cualquier error, fallo o equivocación en un argumento. Es un error serio o una táctica engañosa, y su exposición destruye la argumentación si la maniobra ofensiva no se corrige o se retira.
\end{abstract}

Como se verá más adelante, varios autores han presentado objeciones a este concepto teórico de falacia o han argumentado que las falacias no deberían enseñarse en los cursos de argumentación (Boudry et al., 2015; Finocchiaro, 1981; Hitchcock, 1995; Hundleby, 2010). En el marco de esta discusión sobre la utilidad del concepto de falacia, el propósito de este artículo es ofrecer varias razones por las que creo que sería saludable desechar tal concepto. Aunque, naturalmente, no es posible argumentar de manera concluyente en un solo artículo que toda concepción de las falacias es defectuosa, espero al menos mostrar que hay buenas razones para sospechar de cualquier concepción que se base en clasificaciones de tipos de argumentos falaces.

Comenzaré, en la Sección 2 por exponer una observación ya ampliamente aceptada por muchos teóricos de la argumentación: los argumentos caracterizados habitualmente en las taxonomías de falacias no son siempre falaces. Concluiré que este hecho constituye un problema más serio para el concepto de falacia de lo que usualmente se asume. Después, en la Sección 3, me ocuparé del problema de los criterios de identificación de las falacias, demasiado vagos y subjetivos para sustentar una acusación tan seria como la de falacia. En la Sección 4 argumentaré que los criterios realmente pertinentes para evaluar la calidad argumentativa son ajenos a los catálogos de falacias, de modo que realmente no necesitamos tales catálogos. Y, finalmente, en la Sección 5 me ocuparé de la posible objeción de que, a pesar de todas estas insuficiencias teóricas, la noción de falacia puede ser útil para propósitos pedagógicos.

\footnotetext{
4 Debo admitir que este juicio está basado en observaciones informales de discusiones ordinarias, principalmente en las redes sociales. Sería interesante hacer un estudio para comprobar si ese comportamiento es tan frecuente como creo.
} 


\section{Una taxonomía de incertidumbres}

A primera vista, los catálogos de falacias proporcionan una manera sencilla de detectar argumentos erróneos o engañosos. Uno simplemente debe comprobar si el argumento que tiene delante se corresponde con las características o la estructura de alguno de los argumentos enumerados en un catálogo de falacias; si es así, entonces se trata de una falacia. Tal asunción parece ser la que subyace a las taxonomías de falacias. Si, por ejemplo, nos encontramos con un contraargumento en el que se ataca a la persona que presenta el argumento y no al argumento en sí, entonces podemos identificarlo como un argumento ad hominem y desecharlo por ser falaz. De este modo -se cree-, los catálogos de falacias ofrecen una útil recopilación de argumentos incorrectos.

Esa idea fundamenta algunos trabajos académicos sobre falacias. Por ejemplo, Bordes Solanas, en su definición de falacia, se adhiere a la extendida idea del error inferencial (2011, p. 137):

Falacia def. es un argumento no razonable o racionalmente no convincente, es decir que, aunque puede ser válido, contiene un error inferencial por violar uno o más criterios de buena argumentación.

Como criterio de detección de falacias, Bordes Solanas hace uso de los esquemas argumentativos. Esto se ve claramente cuando afirma que "la presencia de falacias depende exclusivamente de la estructura del argumento (su EA) en un contexto de diálogo" (p. 136). De hecho, la autora enfatiza que cualquier argumento que ejemplifique un esquema argumentativo incluido en su catálogo de falacias es siempre un argumento falaz (p. 138).

El problema con esta idea de que los catálogos de falacias recopilan patrones de argumentos que son siempre falaces en cualquier circunstancia es que es falsa. La mayoría de los teóricos de la argumentación reconocen hoy en día que los argumentos incluidos en las clasificaciones de falacias pueden ser razonables en algunos casos. Ya en una fecha tan temprana como 1979, Toulmin, Rieke y Janik aseguraban (2018, p. 200):

\footnotetext{
Puede que esto inquiete más a algunas personas, pero los argumentos que son falaces en un contexto pueden resultar ser sólidos en otro contexto. Por lo tanto, no podremos identificar ninguna forma de argumentar que sea intrínsecamente falaz. Solo intentaremos indicar por qué ciertos tipos de argumentos son, en la práctica, falaces en uno $\mathrm{u}$ otro tipo de contexto.
}

Posteriormente, el teórico de la argumentación que más ha contribuido al reconocimiento de que muchas de las falacias tradicionales pueden ser razonables en ciertas circunstancias 
es Douglas Walton. Cuando propuso su teoría pragmática de las falacias -basada no solo en elementos lógicos formales sino también en esquemas argumentativos informales y en tipos de diálogos-, Walton desechó la idea de que las falacias son argumentos inherentemente incorrectos y argumentó que se trata más bien de usos incorrectos de argumentos. Así, afirmaba $(1995$, p. 16)

[...] los tipos de argumentación identificados con las diferentes falacias no son siempre argumentos falaces. Por ejemplo, el argumento ad hominem, aunque tradicionalmente haya sido clasificado como una falacia, es en algunos casos un argumento razonable (no falaz).

No es difícil encontrar ejemplos de argumentos ad hominem que son razonables. Walton (p. 40) menciona los ataques a la veracidad de un testigo durante un interrogatorio en un tribunal. Otros autores han afirmado que las apelaciones al carácter de un argumentador pueden ser pertinentes en una discusión (Boudry et al., 2015, p. 437): "En muchos contextos, la plausibilidad de un argumento depende de las credenciales, el contexto personal y las acciones pasadas del hablante". Incluso en la práctica científica, señalan, aunque se describa el procedimiento exacto de un experimento y se difundan los resultados, es necesario confiar en que el científico en cuestión no ha omitido ni manipulado datos o que ha seguido estrictamente el procedimiento (p. 438). Por ello, una acusación fundada de falta de integridad o de comisión de fraudes en el pasado puede echar por tierra -legítimamente- los actuales argumentos de un científico.

Boudry, Paglieri y Pigliucci son especialmente enfáticos en afirmar que esta indeterminación supone un grave problema para las taxonomías de las falacias. Toda teoría de las falacias ${ }^{6}$-aseguran- se enfrenta a un dilema, que ellos denominan "encrucijada de las falacias" (Boudry et al., 2015, p. 435). Por un lado, es posible caracterizar cada falacia de manera que sea claramente inválida o incorrecta -como una pretensión fallida de ser una inferencia deductiva o una inducción fuerte, por ejemplo-. En tal caso, no habrá duda de que cada una de las falacias de los catálogos representa un argumento que no puede ser razonable nunca. Sin embargo, nos encontramos con el problema de que, en las discusiones que tienen lugar realmente en la vida diaria, casi nunca se producen argumentos que

\footnotetext{
5 Aquí y en adelante, las traducciones al español de las citas en inglés son mías.

6 Aunque aquí me limito a las teorías basadas en tipos de argumentos y esquemas argumentativos como la de Walton -por ser las que más han influido en el público general-, las críticas de estos autores también van dirigidas a la pragmadialéctica (pp. 446-449).
} 
se correspondan con las falacias así caracterizadas -de ahí que los ejemplos de los libros de texto resulten muy artificiales-.

La única forma de hacer encajar los argumentos reales en esas categorías pasa por malinterpretar los argumentos en cuestión para atribuirles una mayor fuerza de la que el argumentador pretendía darles. Así, por ejemplo, si uno se encuentra con un argumento plausible basado en signos -tal como "El suelo está mojado, así que probablemente haya llovido"- siempre es posible, si uno no tiene demasiados escrúpulos, interpretarlo como una falacia de afirmación del consecuente -"Si ha llovido, el suelo está mojado; el suelo está mojado; por lo tanto ha llovido"-. Como ya argumentó Finocchiaro, exagerar la fuerza de los argumentos puede llegar a convertirse en una práctica habitual de los libros de texto sobre falacias (1981, p. 16):

Si la práctica discutible es un tipo de argumento inductivo, es decir, uno en el que se afirma que la conclusión está respaldada de manera fuerte, pero no concluyente, por las premisas, entonces se describe la práctica como un tipo de argumento deductivo, es decir, uno en el que se afirma que la conclusión está respaldada de manera concluyente por las premisas. Si la práctica discutible es un tipo de lo que podría llamarse un argumento parcial, es decir, uno en el que se afirma que la conclusión está respaldada solo parcialmente, pero no con demasiada fuerza, por las premisas, entonces la práctica se describe como un tipo de argumento presuntamente inductivamente fuerte. [...] si la práctica discutible es un tipo de no argumento, es decir, que no es un intento de respaldar una proposición con otras, entonces se describe como un argumento en el que se afirma que ciertas proposiciones proporcionan al menos algún respaldo para otra (la conclusión). Finalmente, si la práctica discutible es un argumento que tiene como conclusión un tipo especial de proposición, entonces se describe como un argumento que tiene otra conclusión [...].

La otra rama del dilema es la que caracteriza a enfoques como el de Walton, que ya se ha mencionado. Conscientes del carácter artificioso de los ejemplos presentados en los catálogos tradicionales de falacias, la mayoría de los teóricos de la argumentación hoy en día han incorporado elementos pragmáticos en sus caracterizaciones de falacias, de modo que incluyan argumentos plausibles y criterios lógicos menos estrictos. En este caso, en efecto, se encuentran multitud de casos de falacias en el mundo real. Sin embargo, el precio que se ha pagado es que los esquemas argumentativos ya no sirven como herramienta de identificación sistemática de las falacias como ya hemos visto-, pues la calidad de los argumentos depende de una multitud de factores contextuales. Las ejemplificaciones de un esquema argumentativo determinado pueden ser tanto falaces como razonables. Así que la utilidad de las etiquetas resulta más dudosa. 
Además del argumento ad hominem, Boudry y sus colaboradores presentan ejemplos de otras supuestas falacias. Una de las más conocidas es la falacia ad ignorantiam, que consiste en inferir la verdad de una proposición a partir de la ausencia de pruebas de su negación. Siguiendo la primera rama de la encrucijada que nos presentan los autores, esta falacia puede definirse como un argumento deductivo -la ausencia de pruebas de que $p$ implica necesariamente que no- $p-$, con lo cual sería claramente inválido pero inexistente en las discusiones reales. La alternativa es definirla como un argumento plausible, pero en tal caso su fuerza pasa a depender de asunciones contextuales que no son capturadas en el esquema argumentativo. Es especialmente relevante, en particular, saber cuál es la probabilidad de que hubiéramos encontrado pruebas si la hipótesis fuese cierta. Por ejemplo, la ausencia de pruebas de que haya grupos satánicos que devoran niños es indicativa de que no los hay, ya que si los hubiera sería muy probable que hubiéramos encontrado pruebas. En cambio, la existencia de lagunas en el registro fósil no es una razón a favor del creacionista, ya que las raras condiciones que causan la fosilización hacen muy improbable encontrar los fósiles (p. 441). Nótese que en ambos casos estamos ante el mismo tipo de argumento ad ignorantiam; solo cambian las condiciones pragmáticas y contextuales.

Vemos, así, que, en las teorías más realistas sobre las falacias, la razonabilidad de un argumento no depende de que este ejemplifique un esquema argumentativo o de que pueda caracterizarse con una etiqueta. Este hecho, aunque ya sea ampliamente reconocido, constituye un problema más serio de lo que se ha admitido para los catálogos de falacias. Lo que significa es que las categorías de falacias destacan ciertas características de los argumentos que no constituyen un error lógico. No hay nada de malo per se en apoyarse en la ausencia de pruebas para inferir la ausencia de un fenómeno (ad ignorantiam), o en apelar a ciertas características de un hablante para desacreditarlo (ad hominem) o para confiar en su opinión (argumento de autoridad). Solo en ciertos casos, y debido a factores contextuales, tales argumentos pueden ser incorrectos. Como explican Boudry et al. (p. 434):

Para empezar, las etiquetas mismas que asignamos a las diferentes falacias (ad hominem, ad ignorantiam, post hoc ergo propter hoc, ad verecundiam, etc.) sugieren que una única característica -la más notoria- es la marca distintiva que condena todo el argumento, independientemente de las circunstancias.

En efecto, al rechazar un argumento calificándolo de -por ejemplo- "falacia de autoridad", se está sugiriendo que hay algún problema con los argumentos de autoridad. Si no todos, al menos la mayoría de los argumentos de autoridad deben de ser incorrectos. Sin embargo, eso no es así: los argumentos de autoridad que son buenos no son excepciones. Lo mismo 
sucede con los argumentos ad ignorantiam, los argumentos ad hominem o los argumentos post hoc ergo propter hoc, entre otros muchos. En consecuencia, no hay motivo para seguir hablando de esos tipos de falacias. Imaginemos por un momento que se propusiera el criterio de que los argumentos escritos -frente a los orales- son falaces. Naturalmente, no tardarían en aparecer ejemplos de argumentos escritos que son buenos y por tanto no cumplen ese criterio. ¿No sería lo más razonable abandonar dicho criterio? ¿Qué sentido tendría conservar una categoría de "falacia del argumento escrito"?

Cuando el criterio que determina la presencia de una falacia es el cumplimiento de ciertas condiciones pragmáticas y contextuales, la relevancia del esquema argumentativo desaparece. Nos quedamos, así, con un conjunto de etiquetas que parecen indicar equivocadamente la presencia de un error lógico fundamental que distingue los argumentos falaces de los argumentos correctos, lo que según Boudry et al. "fomenta una interpretación simplista de los argumentos de la vida real" (p. 437). En consecuencia, las categorías de falacias no solo son superfluas sino que resultan incluso perjudiciales para una comprensión adecuada de la calidad de los argumentos (p. 453).

En esta sección, mis argumentos han ido dirigidos a las taxonomías de falacias. ¿En qué medida afectan al concepto mismo de falacia? Si se entienden las falacias como tipos de argumentos incorrectos, pero no es posible especificar de qué tipos se trata -como he sostenido-, entonces la utilidad del concepto de falacia empieza a resultar dudosa. Si las falacias se definen, en general, como tipos de argumentos erróneos, engañosos o no razonables, pero no es posible especificar qué error, engaño o falta de razonabilidad caracteriza a esos tipos de argumentos, deja de estar claro para qué necesitamos tal concepto. El destino de la noción de falacia, por tanto, parece estar irremediablemente unido al de las taxonomías de falacias.

\section{El problema de la identificación}

No obstante, a pesar del hecho de que no exista una correspondencia entre los esquemas argumentativos supuestamente falaces enumerados en los catálogos y las falacias reales, podría decirse que sí disponemos de criterios para identificar las falacias. Por ejemplo, para el caso del argumento ad hominem, Govier explica (2010, p. 160):

Razonar a partir de premisas sobre el trasfondo, la personalidad, el carácter o las circunstancias de las personas para llegar a conclusiones sustanciales sobre sus argumentos o sus teorías supone cometer la falacia ad hominem, a menos que las premisas sean pertinentes para la conclusión porque es sobre la persona o depende de la aceptación de la autoridad o el testimonio de esa persona. 
Así pues, el criterio parece ser que, si las apelaciones personales son irrelevantes para la conclusión del argumento, entonces se comete la falacia ad hominem. De un modo similar, Walton especifica cuándo el argumento ad ignorantiam deja de ser razonable ${ }^{7}$ (1995, pp. 277-278):

El error del ad ignorantiam, o argumento ad ignorantiam erróneo, se da cuando el investigador salta con demasiada rapidez hacia adelante y llega a una conclusión dogmática sin atravesar los pasos de la investigación o del diálogo que se requieren para establecer la conclusión por la que se indaga.

Es más, aunque en la sección anterior se hayan mostrado algunos ejemplos de formas argumentativas supuestamente falaces que a veces son razonables, no se ha mostrado que esto suceda con todas las falacias habituales de los catálogos. De hecho, parece evidente que algunas de tales formas argumentativas son falaces siempre y en todo caso. El mismo Walton (p. 210) distingue entre tipos de argumentos que pueden ser razonables o falaces, en función de las circunstancias, y tipos de argumentos que son falaces siempre. ¿Acaso existe algún ejemplo razonable de -pongamos por caso- hombre de paja o de generalización precipitada? De acuerdo con Walton (p. 57), la falacia del hombre de paja consiste en "hacer que el argumento de tu oponente parezca malo identificándolo (incorrectamente) con una opinión que le parece repugnante o peligrosa a prácticamente cualquiera”. En cuanto a la falacia de la generalización precipitada, consiste en el error de "generalizar inductivamente a partir de una muestra demasiado pequeña de pruebas"8 (p. 53). No cabe duda de que todos los casos en los que un argumentador haga tales cosas serán falaces.

Ciertamente, no existen casos razonables de esas dos falacias -como tampoco de otras, como la falsa analogía o la falsa causa-. Pero la razón por la que todas las ejemplificaciones de tales patrones argumentativos son siempre falaces nos conduce al segundo gran problema de las falacias: su identificación. Esas falacias suelen ser caracterizadas en términos evaluativos, no descriptivos. Una falacia ad hominem - se nos dice-consiste en apelar a características "irrelevantes” del argumentador. Una generalización precipitada es la que se realiza sobre una muestra "demasiado pequeña" o "insuficiente". Un hombre de paja consiste en una representación "incorrecta" o una "tergiversación” de la tesis del oponente. Sin duda, lo que es irrelevante, insuficiente o incorrecto es malo por definición. ¿Pero cómo

\footnotetext{
7 Conviene aclarar que, para Walton, eso no implica automáticamente que se cometa una falacia. Puede tratarse de un simple error, que él distingue de la falacia. Pero no me enredaré con esta cuestión aquí.

8 La generalización precipitada también incluye el error de aplicar una regla general a casos excepcionales (Walton, 1995, p. 54), pero podemos limitarnos a su primer sentido para no alargar la discusión.
} 
podemos identificarlo? Una razón que para mí es irrelevante puede ser muy pertinente para mi interlocutor en una discusión. ¿El hecho de que un político ha cometido adulterio es pertinente para decidir si debemos votarlo o no? ¿A qué criterios objetivos podríamos apelar para dirimir la cuestión de la pertinencia?

Pensemos, por ejemplo, en una falacia aparentemente tan indiscutible como el hombre de paja. Desde luego, tergiversar los puntos de vista de otra persona es algo que nunca se debe hacer en una discusión. ¿Pero cuándo puede asegurarse que se ha producido una tergiversación? ¿Somos culpables de cometer la falacia del hombre de paja siempre que nuestro interlocutor proteste porque no se siente reflejado en nuestras críticas? Supongamos que, en una manifestación ciudadana cuyas reivindicaciones políticas yo apoyo, se producen incidentes violentos -que yo no apruebo-. Mi interlocutor, contrario a las reivindicaciones de los manifestantes, menciona esos sucesos violentos para desacreditarlas. En mi defensa, yo argumento que tales sucesos son irrelevantes para juzgar las propuestas políticas, pero entonces él pasa a explicarme que el carácter mismo de las reivindicaciones de los manifestantes implica el recurso a la violencia. Yo frunzo el ceño. Me niego a aceptar que mis ideas políticas tengan tales implicaciones $y$, en consecuencia, siento que mis convicciones no se ven reflejadas en absoluto en la caracterización que acaba de exponer. ¿Puedo acusarle de cometer la falacia del hombre de paja? ¿Y si resulta que tiene razón, y lo que ocurre en realidad es que yo no comprendía suficientemente bien las implicaciones de mis ideas políticas?

La solución a este embrollo, por supuesto, es seguir argumentando. Deberemos intercambiar argumentos a favor y en contra de tal interpretación de mis ideas hasta que -si hay suerte- logremos un acuerdo razonado. No obstante, ese intercambio de críticas y argumentos desde diferentes perspectivas en ningún momento justifica la aparición en el diálogo de la palabra "falacia". Como indiqué en la Introducción, acusar a alguien de cometer una falacia implica mucho más que decirle que uno no está de acuerdo con sus argumentos, y de hecho también implica más que decirle que uno considera que sus argumentos son deficientes. Es una acusación de haber infringido unas supuestas leyes de la lógica firmemente establecidas. Y, naturalmente, es una acusación muy seria. Como afirma Vega Reñón (2013, p. 22):

Nuestros usos cotidianos de los términos 'falaz' y 'falacia' abundan en su significado crítico o peyorativo: insisten en la idea de que una falacia es algo en lo que se incurre o algo que se comete, sea un engaño o sea algo censurable hecho por alguien con la intención de engañar.

Naturalmente, si dispusiéramos de criterios objetivos y precisos de identificación de falacias, entonces esas acusaciones tan serias estarían justificadas - del mismo modo que podemos 
mandar callar sin remordimientos a quien afirme que dos más dos es igual a seis-. Pero el hecho es que no tenemos tales criterios. Lo único que tenemos, como hemos visto, es un conjunto de esquemas argumentativos que no sirven para distinguir entre falacias y argumentos razonables, unas cuantas referencias vagas al contexto y varios términos evaluativos -como "irrelevante" o "incorrecto"- de difícil aplicación práctica.

Puede que una analogía con las normas morales ayude a comprender el problema que suponen los términos evaluativos en los criterios de las falacias. En su estudio sobre las reglas prácticas, Goldman (2002) distingue entre tres tipos de reglas. En primer lugar están las reglas genuinas fuertes, que "establecen condiciones suficientes para hacer o abstenerse de hacer algo" (p. 15). Se trata de reglas universales que describen unas condiciones en términos no morales, condiciones que pueden ser reconocidas sin dificultad y que prescriben un curso de acción. Servirse de estas reglas implica -afirma Goldman- renunciar a hacer una valoración propia de la situación; las reglas fuertes deben cumplirse literalmente y sin excepción -o, al menos, sin ninguna excepción que no esté establecida previamente en la regla misma-. Algunos ejemplos son las normas de jubilación obligatoria o las prohibiciones de consumo de alcohol en eventos públicos. Por otro lado, existen reglas generales (rules of thumb), que se caracterizan por ser meramente orientativas y por tener excepciones indeterminadas. Las reglas generales no determinan las acciones sino que su aplicación depende del buen juicio del agente. En consecuencia, lo que hacen estas reglas es simplemente recordarnos factores que podrían ser moralmente relevantes, aunque las reglas mismas no tengan ningún peso (p. 14). Un ejemplo de regla general es "Di la verdad". Y, por último, tenemos pseudorreglas, que no enuncian condiciones en términos descriptivos y neutros sino en términos normativos (p. 16). Aunque la aplicación de estas reglas sea universal -sin excepciones- esto solo se debe al hecho de que sus condiciones están formuladas en términos moralmente cargados. En realidad, aquí también es necesario el juicio del agente, esta vez para interpretar los términos normativos y determinar si corresponden a una determinada situación. Un ejemplo es la regla "No se debe asesinar" -si "asesinar" se define como matar indebidamente-. Según Goldman, las pseudorreglas "pueden enmascarar las cuestiones morales auténticas y hacer que nos sintamos demasiado seguros en nuestros juicios" (p. 18). Y explica (p. 13):

El razonamiento moral debe comenzar con descripciones no normativas de acciones o situaciones y terminar con prescripciones morales. Si, en lugar de ello, empezamos con descripciones de situaciones que están formuladas en términos morales, entonces estamos invitando al desacuerdo, y debemos razonar sobre si esas descripciones morales se aplican apropiadamente a las situaciones en cuestión. 
Por lo tanto, concluye Goldman, tanto las reglas generales como las pseudorreglas son prescindibles. El auténtico razonamiento moral tiene lugar sin ellas.

Pues bien, no es difícil reparar en que los criterios de identificación de falacias que incluyen términos como "irrelevante", "insuficiente", "demasiado" o "incorrecto" son equivalentes a las pseudorreglas de Goldman. Esos criterios no sirven para distinguir entre argumentos razonables y argumentos falaces sobre la base de características inherentes a los argumentos mismos. No son criterios objetivos que estén por encima de los desacuerdos entre argumentadores. Son pseudocriterios. Y su existencia sirve para poco más que ocultar el hecho de que las acusaciones de falacias son, a fin de cuentas, juicios discutibles.

\section{La cuestión de la evaluación}

De lo que no cabe ninguna duda es que, en las discusiones cotidianas, hay argumentos muy malos y tácticas engañosas. Recordemos, sin ir más lejos, un intercambio muy comentado que tuvo lugar en el programa "Chester in love" de la cadena televisiva española Cuatro entre la periodista Mercedes Milá y el científico y divulgador José Miguel Mulet el 5 de marzo de 2017. El tema de la discusión era el libro La enzima prodigiosa, que Milá defendía y Mulet criticaba. Después de que Mulet presentara varios argumentos que mostraban que el libro incurre en falsedades, Milá comenzó su intervención de la siguiente forma: "Lo primero que te digo es que te leas el libro y adelgaces porque estás gordo".

Resulta difícil encontrar un caso más evidente que este de apelación irrelevante a las características del argumentador. En la mente del lector sin duda habrá irrumpido con viveza una expresión muy conocida: "falacia ad hominem". Y, naturalmente, varios medios de comunicación y blogs se apresuraron a explicarnos -como si hiciera falta- que Milá había cometido esa falacia. Sin embargo, la respuesta de Mulet no consistió en acusar a la periodista de recurrir a falacias sino en un comentario que -en mi opinión- fue una reacción ejemplar ante el ataque de la periodista:

Es muy curioso que me digas esto, porque de toda la argumentación que he dicho lo único criticable que has encontrado es el tamaño de mi cintura.

No hay aquí etiquetas vacías que solo servirían para desacreditar y silenciar a su interlocutora. En lugar de ello, lo que vemos es un mensaje informativo que identifica el problema central del comentario de Milá y que insta a la periodista a volver al terreno de la discusión razonable: Mulet señala que Milá no ha tomado en consideración ninguno de sus argumentos. Frente a la poca ilustrativa exclamación de “¡falacia ad hominem!” -que habría logrado 
el efecto retórico de hacer que el público viera a Milá como una persona poco razonable, pero poco más-, la réplica de Mulet aborda directamente la irrelevancia de esa referencia a sus características físicas y devuelve la atención a los argumentos que él ha expuesto. Los periodistas y divulgadores que corrieron a explicarnos que la intervención de Milá era una falacia ad hominem en realidad no estaban explicando nada; Mulet ya había indicado con mayor claridad que ellos cuál era el problema.

Lo que muestra este ejemplo no es simplemente que sea conveniente evitar hacer acusaciones de falacias cuando argumentamos. El hecho de que podamos argumentar con rigor sin recurrir a las categorías de falacias, incluso ante los casos más flagrantes de sinrazón, y que en tales casos sea más ilustrativo evitar apelar a tales categorías, pone en cuestión el valor teórico de las clasificaciones de falacias. Si las categorías de falacias no proporcionan una explicación adecuada de los defectos de ciertos argumentos, eso nos da una buena razón para sospechar que esas categorías tampoco nos sirven para distinguir entre argumentos buenos y malos. Como ya sostuvo el teórico de la argumentación David Hitchcock (1995, p. 325): "las etiquetas de falacias no son necesarias para el ejercicio del pensamiento crítico; todo lo que puede decirse con el uso de esas etiquetas puede decirse sin ellas, y en general más claramente". En efecto, como ilustra el ejemplo que acabamos de ver, si prescindimos de esas etiquetas no solo no carecemos de ninguna herramienta esencial para la práctica argumentativa razonable sino que somos más precisos e informativos.

¿Por qué esto es así? Como he intentado mostrar en la Sección 1, las caracterizaciones de patrones de argumentos y los esquemas argumentativos resultan muy poco útiles para detectar falacias, ya que se corresponden igualmente con argumentos razonables. Eso significa que, cuando -intuitivamente- vemos que algo falla con un argumento, lo que nos llama la atención no puede ser lo que recogen esos criterios de las taxonomías de falacias. Cuando, en un juicio, se desacredita a un testigo porque posee un largo historial de mendacidad, nadie siente la tentación de usar la etiqueta de "falacia ad hominem" -a pesar de que su estructura es la misma-. La evaluación del argumento tiene lugar primero, y solo después de haber decidido que el argumento es malo le atribuimos la etiqueta de una falacia. Este es un problema de las categorías de falacias que ya señaló Vega Reñón (2013, p. 21):

[...] los casilleros de falacias son hormas de reconocimiento a posteriori, puesto que, en razón de las complicaciones ya sabidas, no cabe asegurar que todos los argumentos de una determinada forma lógica, y con independencia de su contexto particular de uso, sean falaces o no lo sean. 
¿Cómo identificamos, entonces, los malos argumentos? En 1977, en los orígenes de la lógica informal, Johnson y Blair (1994) propusieron tres criterios de calidad para los argumentos, el incumplimiento de cualquiera de los cuales tiene como resultado un mal argumento. De acuerdo con estos tres criterios, las premisas del argumento deben ser aceptables, deben ser pertinentes para la conclusión y deben ser suficientes para proporcionar un apoyo a la conclusión (p. 55). El enfoque de Johnson y Blair para el estudio de los argumentos estaba basado en las falacias, de modo que sus criterios servían en realidad para explicar y clasificar cada tipo de falacia. No obstante, los criterios que propusieron han hecho fortuna en la disciplina de la lógica informal como criterios del buen argumento independientemente de cualquier referencia a la idea de falacia.

Visto en retrospectiva, no resulta sorprendente que los criterios de aceptabilidad, pertinencia y suficiencia terminaran por desvincularse de las falacias. Esos criterios partían de la pregunta de qué es un buen argumento, en lugar de basarse en una tipología de errores -tales como la equivocidad, el defecto formal, la generalización precipitada o las tácticas de distracción, encabezados habituales de las clasificaciones de falacias-. Además, parecían articular en términos concretos el fundamento de nuestras evaluaciones intuitivas, tanto positivas como negativas, de los argumentos.

De este modo, disponemos de unos criterios para distinguir buenos y malos argumentos y de unos conceptos para expresar nuestros juicios sobre la calidad de los argumentos. Mulet apeló implícitamente al criterio de pertinencia para señalar el defecto en la intervención de Milá. Una vez detectado el error con ayuda de esos criterios, la asignación posterior de la etiqueta de una falacia no aporta nada nuevo. Esos criterios proporcionan información sobre las razones por las que un argumento es malo; las etiquetas de falacias no. Naturalmente, "aceptable", "pertinente" y "suficiente" son términos evaluativos y por tanto -como he argumentado en la sección anterior- los criterios no producen veredictos definitivos sobre la calidad de los argumentos. Por eso, poner sobre la mesa un juicio evaluativo sobre un argumento es el primer paso para una (probable) discusión sobre dicho juicio. En cambio, una escueta acusación de falacia no suele dar pie a discutir nada más.

Uno podría pensar, sin embargo, que esos criterios son demasiado generales y abstractos para capturar las particularidades de los diferentes tipos de argumentos. Al fin y al cabo, la evaluación de la pertinencia en un argumento ad hominem es bastante diferente de la evaluación de la pertinencia en una generalización a partir de una muestra. Eso es cierto, pero tampoco para eso necesitamos un catálogo de falacias: basta con un catálogo de tipos de argumentos que detalle las formas específicas de evaluar cada uno. Esto ya ha sido elaborado por algunos teóricos de la argumentación cuyo enfoque se basa en los esquemas argumentativos, entre quienes destaca Douglas Walton (Walton et al., 2008). Como herramienta de 
evaluación de los diferentes tipos de argumento, Walton ha propuesto, para cada uno de ellos, una serie de preguntas críticas específicas, que son preguntas que un oponente puede hacer al argumentador para comprobar la solidez de su argumento. Este mismo enfoque ha sido adoptado por Marraud (2013), quien presenta un catálogo de 25 tipos de argumentos con sus correspondientes preguntas críticas. En mi opinión, las preguntas críticas son herramientas idóneas para evaluar adecuadamente la calidad de los argumentos y poder distinguir entre buenos y malos argumentos. Pero las preguntas críticas sirven para evaluar argumentos concretos en su contexto, no esquemas o tipos de argumentos. Ni en el caso de Walton, Reed y Macagno ni en el caso de Marraud encontramos una clasificación de falacias, y tampoco se la echa en falta?.

\section{5. ¿Son útiles las falacias?}

Por último, una objeción común es que el concepto de falacia, aun a pesar de sus debilidades teóricas, puede ser una herramienta útil para la enseñanza de las habilidades argumentativas y el pensamiento crítico -quizá a modo de heurísticas-. De hecho, el valor pedagógico de las falacias ha sido defendido por autores como Blair (1995), quien sostiene que pueden ser útiles para aprender a interpretar y evaluar argumentos, siempre y cuando su enseñanza no se lleve a cabo de manera simplista y superficial -en cuyo caso, admite (p. 335), hace más mal que bien-.

Mi respuesta a esta objeción será doble -y, dentro de lo posible, breve-. En primer lugar, creo que cualquier tratamiento pedagógico de la enseñanza de las falacias que no sea simplista y superficial será en la práctica indistinguible de los enfoques basados en esquemas argumentativos que hemos visto al final de la sección anterior, con la única salvedad de que se usará (innecesariamente) la palabra "falacia". Aplicar de forma seria y responsable el enfoque de las falacias en la enseñanza de la argumentación incluye reconocer que muchos de los patrones supuestamente falaces de los catálogos caracterizan tipos de argumentos que son razonables en determinadas circunstancias -de modo que, en realidad, no se estará enseñando otra cosa que esquemas argumentativos-, y tales circunstancias deben especificarse en la forma de algo similar a las preguntas críticas de Walton y Marraud. Algunas falacias no se ajustan a ningún esquema argumentativo, como el hombre de paja y la equivocidad, pero para

\footnotetext{
9 Recordemos que las falacias y los malos argumentos (o argumentos incorrectos) no son conceptos equivalentes. Como se indicó en la Introducción, las falacias son tipos de argumentos incorrectos -y eso es precisamente lo que estoy poniendo en duda aquí que exista-. Asimismo, tradicionalmente se han incluido en el concepto de falacia otras condiciones aparte de la ser un mal argumento, como la de que aparente ser un argumento válido (Hamblin, 2016, p. 19) o que se cometa con "una notable frecuencia" (Woods, 2004, p. 3). Si, en cambio, alguien propusiera usar el término "falacia" como equivalente a "argumento incorrecto", mi respuesta sería simplemente que en tal caso el término "falacia" es ocioso e innecesario.
} 
abordar las causas de tales problemas es suficiente con enfatizar la importancia de principios dialécticos como el principio de caridad y de la precisión en la comunicación lingüística. Nada se gana, por tanto, al usar etiquetas de falacias, y es demasiado lo que se pierde debido a las connotaciones críticas y disruptivas que -según he argumentado- tienen.

En segundo lugar, conviene señalar que la cuestión de si el concepto de falacia es útil o no en la enseñanza es empírica. Las buenas intenciones o la apelación a toda una tradición lógica no bastan. Debemos comprobar si, en efecto, los estudiantes que reciben lecciones sobre las falacias terminan por argumentar mejor y poseer un mayor pensamiento crítico que antes.

Lamentablemente, hasta donde yo sé, no existen estudios específicos sobre los efectos de la enseñanza de las falacias. Mercier y sus colaboradores ${ }^{10}$, en un artículo en el que exploran las perspectivas para la enseñanza de la argumentación desde el punto de vista de su teoría argumentativa del razonamiento, consideran las falacias y afirman (Mercier et al., 2017, p. 10): "No conocemos ninguna prueba que sugiera que la enseñanza de las falacias produce una mejoría de la capacidad de razonamiento individual". De hecho, estos autores ven improbable que la enseñanza de las falacias sirva para evitar que los estudiantes cometan falacias en sus propios argumentos o para que aprendan a detectar falacias en los argumentos de los demás, ya que "el concepto mismo de falacia es problemático" (p. 9).

Hay, sin embargo, estudios sobre la eficacia de los cursos de pensamiento crítico tal como se han realizado hasta ahora en Norteamérica -que considero pertinentes, aunque desde luego no concluyentes, porque muchos de esos cursos incluyen una parte sobre falacias-. Los resultados no son alentadores. Benjamin Hamby (2016) presenta un resumen de varios de esos estudios y concluye que "parece claro que, a pensar de esfuerzos intensos y generalizados, los estudiantes no se están convirtiendo en mejores pensadores críticos como resultado de tomar un único curso en la universidad" (p. 1). La tesis de Hamby no es que no deba enseñarse pensamiento crítico, sino que no está justificado seguir haciéndolo de la misma forma como se ha hecho hasta ahora (p. 3). En concreto, los resultados empíricos que comenta Hamby muestran -entre otras cosas- que la enseñanza de principios y conceptos abstractos -tales como las falacias- sin un contenido específico produce unos beneficios muy pobres o inexistentes en los estudiantes.

Otro motivo de preocupación nos ofrece Hundleby (2010), quien analizó 30 libros de texto de pensamiento crítico actualmente en uso - de nuevo, en Norteamérica-y descubrió que una inmensa mayoría de ellos presentan al menos tres de los siguientes rasgos (pp. 288289): (a) ninguna mención a la posibilidad de corregir un argumento defectuoso, (b) ejem- 
plos muy cortos o descontextualizados, (c) ejemplos artificiales y (d) ejercicios que asumen que los argumentos que ejemplifican esquemas argumentativos que pueden ser falaces son siempre falacias. Esto, naturalmente, no constituye una razón en contra de las actuales teorías de las falacias -que no comparten esas características- sino únicamente contra la forma en que se están enseñando las falacias. No obstante, mi impresión es que el concepto mismo de falacia -teóricamente deficiente, con una fuerte connotación crítica y con una pretensión de objetividad-se presta fácilmente a tales tratamientos simplistas en el aula, como sugiere la propia Hundleby (p. 293).

Además -aunque aquí ya entremos en el terreno de los indicios meramente anecdóticos-, varios profesores de argumentación han mostrado sus preocupaciones sobre los resultados en sus alumnos de la enseñanza de las falacias. López y Vicuña (2006), dos profesores de filosofía en Chile, se encontraron ante la difícil tarea de contribuir a una educación por la democracia en un país recién salido de una de las peores dictaduras de Sudamérica y pensaron que la mejor forma de hacerlo era comenzar por la enseñanza de las falacias argumentativas. No tardaron en darse cuenta de que "los estudiantes universitarios solían usar su conocimiento de las falacias para encontrar errores en sus oponentes y reforzar sus propias creencias" (p. 213). El resultado fue que "en lugar de ser críticos con sus propias creencias, los estudiantes solían encontrar falacias en los textos que iban en contra de ellas, $y$ de este modo reforzaban su propio dogmatismo" (Ibid.).

Una experiencia similar relata Hitchcock (1995), quien se opone a la inclusión de las falacias en los cursos de argumentación (pp. 319-320):

En cualquier fragmento de texto, los estudiantes presentaban más de una etiqueta de falacia para un único error. Lo que es peor, yo era incapaz de averiguar cuál de las etiquetas era correcta; los tipos de falacias reconocidos en nuestra taxonomía aparentemente no eran mutuamente excluyentes. Lo que es aún peor, cuando incluí en un examen algunos fragmentos que no contenían ninguna falacia en absoluto, los estudiantes sin vacilar identificaron la falacia y fueron capaces de argumentar a favor de su presencia de manera tan convincente como en el caso de los fragmentos verdaderamente falaces. Aparentemente los estudiantes eran capaces de (y estaban dispuestos a) encontrar una falacia en cualquier sitio.

Como ya he admitido, nada de lo que he expuesto en esta sección constituye una prueba concluyente de la inutilidad o del carácter dañino de las falacias. Sin embargo, creo que el conjunto proporciona indicios suficientes para dudar de su utilidad, sobre todo a la luz de las insuficiencias teóricas mostradas en las secciones anteriores. Si, aun así, alguien insiste 
en defender que el concepto de falacia resulta útil en la enseñanza de la argumentación, creo que debe proporcionar pruebas empíricas de tal afirmación.

\section{Conclusión}

En el presente artículo me he unido a las voces críticas con el concepto de falacia que han surgido en el campo de los estudios de la argumentación. Mi propósito ha sido contribuir a la discusión con varias razones que señalan en la dirección de un abandono del término "falacia". En particular, he dirigido mis críticas hacia una concepción de las falacias como tipos de argumentos objetivamente erróneos, ya que considero que es la concepción más extendida entre los estudiantes de argumentación y el público general. He argumentado que: (1) muchas de las caracterizaciones de las falacias en las taxonomías no identifican únicamente tipos de argumentos incorrectos, sino también muchos argumentos razonables; (2) las caracterizaciones que no adolecen del defecto anterior están expresadas en términos evaluativos, lo que dificulta un acuerdo sobre si se aplican a un determinado argumento o no; (3) el concepto de falacia es en realidad prescindible en teoría de la argumentación; y (4) no está nada claro que las taxonomías de falacias sean útiles para enseñar adecuadamente la argumentación.

En algunos puntos he hablado sobre el concepto de falacia y en otros sobre las taxonomías de falacias. Como he indicado al final de la Sección 2, considero que ambas cosas están indisolublemente unidas. No tiene sentido mantener el concepto de falacia si descubrimos que no es posible elaborar una taxonomía satisfactoria de falacias. Las falacias son tipos de argumentos incorrectos, así que cualquier concepción de las falacias debe incluir una clasificación de esos tipos. Como espero que haya quedado claro, no niego la existencia de argumentos buenos y malos. Solo he criticado la idea de tipos de argumentos que son incorrectos debido a una característica que todos ellos tienen en común y que puede detectarse de manera objetiva.

Mi conclusión es que, en ausencia de tales categorías generales de malos argumentos, no hay otra opción que prestar atención a los argumentos concretos en sus respectivos contextos para evaluar su calidad. No es posible el uso de heurísticas o atajos mentales. Argumentar bien exige un esfuerzo y buen juicio.

\section{Agradecimientos}

Una versión anterior de este artículo fue presentada en el Congreso Internacional de Argumentación, Aprendizaje y Educación "Argumentar para pensar, aprender y convivir en un mundo complejo", celebrado los días 13 y 14 de enero de 2020 en la Universidad Alberto Hurtado (Chile). Agradezco a los asistentes el interés que mostraron y sus comentarios, 
que me ayudaron a desarrollar mejor mis ideas. También agradezco a Hubert Marraud que leyera el artículo y me ayudara con sus observaciones. Este trabajo fue posible gracias al proyecto CONICYT/FONDECYT de Postdoctorado n. 3190149 del gobierno de Chile, así como el proyecto PGC2018-095941-B-I00, "Prácticas argumentativas y pragmática de las razones," del Ministerio de Ciencia, Innovación y Universidades - Agencia Estatal de Investigación (España).

\section{Referencias}

Blair, J. A. (1995). The place of teaching informal fallacies in teaching reasoning skills or critical thinking. En H. V. Hansen y R. C. Pinto (Eds.), Fallacies: Classical and contemporary readings (pp. 328-338). The Pennsylvania State University Press.

Bordes Solanas, M. (2011). Las trampas de Circe: Falacias lógicas y argumentación informal. Cátedra.

Boudry, M., Paglieri, F. y Pigliucci, M. (2015). The fake, the flimsy, and the fallacious: Demarcating arguments in real life. Argumentation, 29(4), 431-456.

Finocchiaro, M. A. (1981). Fallacies and the evaluation of reasoning. American Philosophical Quarterly, 18(1), 13-22.

Goldman, A. H. (2002). Practical rules. Cambridge University Press.

Govier, T. (2010). A practical study of argument. Wadsworth Cengage Learning.

Hamblin, C. L. (2016). Falacias (H. Marraud, Trad.). Palestra.

Hamby, B. (2016). Why NOT teach critical thinking. En P. Bondy y L. M. Benacquista (Eds.), Argumentation, Objectivity, and Bias: Proceedings of the 11th International Conference of the Ontario Society for the Study of Argumentation (OSSA), 18-21 May 2016 (pp. 1-7). OSSA.

Hitchcock, D. (1995). Do the fallacies have a place in the teaching of reasoning skills or critical thinking? En H. V. Hansen y R. C. Pinto (Eds.), Fallacies: Classical and contemporary readings (pp. 319-327). The Pennsylvania State University Press.

Hundleby, C. (2010). The authority of the fallacies approach to argument evaluation. Informal Logic, 30(3), 279-308. 
146 - Cogency, Journal of reasoning and argumentation

Johnson, R. H. y Blair, J. A. (1994). Logical self-defense. McGraw-Hill.

López, C. y Vicuña, A. M. (2006). The pragma-dialectical ideal of reasonableness and an education for critical thinking and for the building of a moral community. En P. Houtlosser y A. van Rees (Eds.), Considering pragma-dialectics (pp. 211-222). Lawrence Erlbaum Associates.

Marraud, H. (2013).¿Es lógic@? Análisis y evaluación de argumentos. Cátedra.

Mercier, H., Boudry, M., Paglieri, F. y Trouche, E. (2017). Natural-born arguers: Teaching how to make the best of our reasoning abilities. Educational Psychologist, 52(1), $1-16$.

Toulmin, S., Rieke, R. y Janik, A. (2018). Una introducción al razonamiento (J. Á. Gascón, Trad.). Palestra.

Vega Reñón, L. (2013). La fauna de las falacias. Trotta.

Walton, D. N. (1995). A pragmatic theory of fallacy. University of Alabama Press.

Walton, D. N., Reed, C. y Macagno, F. (2008). Argumentation schemes. Cambridge University Press.

Woods, J. (2004). The death of argument. Springer Science \& Business Media. 